BMJ Open Sport \& Exercise Medicine

\title{
Concussion reporting behaviours of community college student-athletes and limits of transferring concussion knowledge during the stress of competition
}

\author{
Nancy Resendes Chinn, ${ }^{1}$ Paul Porter ${ }^{2}$
}

\begin{abstract}
To cite: Chinn NR, Porter P. Concussion reporting behaviours of community college student-athletes and limits of transferring concussion knowledge during the stress of competition. BMJ Open Sport Exerc Med 2016;2: e000118. doi:10.1136/ bmjsem-2016-000118
\end{abstract}

- Prepublication history for this paper is available online. To view these files please visit the journal online (http://dx.doi.org/10.1136/ bmjsem-2016-000118).

Accepted 1 August 2016

CrossMark

\begin{abstract}
${ }^{1}$ Disability Resources Department, Santa Rosa Junior College, Santa Rosa, California, USA

2Department of Education, Sonoma State University, Rohnert Park, California, USA
\end{abstract}

Correspondence to Dr Nancy Resendes Chinn; nchinn@santarosa.edu

\section{ABSTRACT}

Concussion education for student-athletes is mandated by several states and is becoming an integral component of concussion management programmes; however, little is known about student-athlete concussion knowledge and self-reporting of suspected concussion. This study explored to what extent collegiate student-athletes are knowledgeable on the topic of concussion, the relationship between having concussion knowledge and reporting behaviours, and factors contributing to not reporting when education has been provided.

Method: Mixed method explanatory design. The Rosenbaum Concussion Knowledge and Attitudes Survey was administered to 986 community college student-athletes from 6 sports. Follow-up qualitative interviews were conducted using purposive sampling.

Results: Concussion knowledge scores positively correlated with number of times concussion education was received, but were not associated with reporting of concussion. Of respondents with a history of concussion, $64 \%$ stated that they reported all of their concussions. The highest ranked reason given for not reporting concussion was, "I was into the game/ practice and didn't realize I had a concussion at the time." Qualitative analysis revealed physiologically related and attitudinal factors particular to competition that precluded participants' identification and reporting of concussion.

Conclusions: Despite receiving concussion education, student-athletes may not be cognizant of a possible concussion particularly during the stress of competition. Results indicate that alternate methods of providing concussion education that can affect knowledge transfer should be explored: providing education in the settings where student-athletes practice and compete, incorporating a kinaesthetic or procedural learning approach to concussion education, and addressing the social and attitudinal aspects of concussion reporting.

\section{INTRODUCTION}

Early identification of a possible concussion is paramount to avoiding serious

\section{Summary of new findings}

- Physiological and attitudinal influences such as 'adrenaline', 'in the zone', 'instinct', 'selfevaluation', duty to 'family' and 'denial' can affect concussion reporting.

- The common experience of 'self-evaluation' following suspected concussion should be considered as a potential signal for self-reporting.

- Concussion education that incorporates procedural learning in the actual setting of play deserves exploration to determine efficacy and viability.

consequences. ${ }^{1}$ The dissemination of concussion education to athletes is currently viewed as integral to facilitating reporting and early diagnosis, and has been considered a "mainstay of progress in the field" (ref. 2, p. 255). Educational programmes have been developed and legislation enacted ${ }^{3}$ to ensure that student-athletes receive education on the topic of concussion. The National Collegiate Athletic Association now mandates yearly education for student-athletes, ${ }^{4}$ as does the California Community College Athletic Association. ${ }^{5}$ These efforts have been implemented in the hopes that increased concussion knowledge will enhance student-athlete awareness of symptoms and risks of concussion, thereby increasing reporting. ${ }^{6}$ Some studies indicate that educational programmes are indeed successful in increasing concussion knowledge in student-athletes. ${ }^{7} 8$ More recently, studies have questioned the efficacy of increasing concussion knowledge alone without addressing cultural attitudes that influence reporting behaviours. ${ }^{9}{ }^{10}$ The inclusion of a "socialecological framework" (ref. 9, p. 884) where social norming and the concussion reporting environment are considered is now viewed as integral to concussion education approaches. ${ }^{11} 12$ 
Over 75000 community college student-athletes participate in intercollegiate sports each year in the USA. Three primary governing bodies oversee community college athletics: the National Junior College Athletic Association, serving 525 colleges in 24 regions; the California Community College Athletic Association, serving 105 colleges in California; and the Northwest Athletic Association of Community Colleges, serving colleges in Oregon, Washington and the Canadian province of British Columbia. ${ }^{13}$ Despite the lack of fanfare and financial gains of community college athletics, nearly $60 \%$ of these institutions continue to support such programmes, ${ }^{14}$ and the numbers of students engaging in community college athletics can be expected to continue to expand. ${ }^{13}$ Although increasing numbers of students are participating in community college athletics, research at this level remains limited. ${ }^{13}$

This study focused on understanding concussion education at community colleges, and in particular, knowledge levels of these student-athletes. The purpose of this mixed method study was to understand the relationship between level of concussion knowledge and reporting behaviours in community college student-athletes. The study sought to identify why student-athletes did not report a possible concussion, despite being provided concussion education.

\section{METHODS}

\section{Procedures}

A mixed method explanatory design was used. Explanatory design allows for qualitative data to "explain or build upon initial quantitative results” (ref. 15, p. 71). Quantitative data were collected first (phase I) in the form of an online survey, followed by nine in-person semistructured interviews of selected participants (phase II). A total of seven community colleges were selected based on two criteria: (1) demographics, allowing for representation of urban, suburban and rural areas, and (2) institutional usage of computerised baseline testing. The use of computerised baseline testing made the administration of computerised surveys a convenient methodology for gathering data. The principle investigator (PI) met with each head athletic trainer at the respective college and provided training in administration procedures for obtaining written consent and administration of the online assessment tool. Each participant signed a consent to participate in research study form per institutional review board guidelines. The survey was administered in each college's computer laboratories prior to the student-athletes participating in baseline testing and prior to participating in concussion education for the fall 2014 season. Participants were not compensated for their participation.

\section{Participants}

Phase I

Participants were 986 student-athletes enrolled for the fall 2014 semester in one of the following intercollegiate sports: football, men's soccer, women's soccer, women's volleyball, men's water polo and women's water polo. All student-athletes in attendance at the mandatory baseline testing at their respective colleges who were invited to participate in the research completed phase I of the study. Men comprised $76 \% \quad(\mathrm{n}=749)$ of study participants, 23\% ( $\mathrm{n}=229)$ were women and $0.31 \% \quad(\mathrm{n}=3)$ selected other.

\section{Phase II}

The population studied in phase II was a sample of nine individuals who participated in phase I. Results of quantitative analysis guided the selection of participants. Participants were selected for interview using purposive sampling. In purposive sampling, participants are selected based on their experience with a central phenomenon being explored. ${ }^{16}$ The finding that participants did not self-report possible concussions despite receiving concussion education was selected for further exploration. Therefore, the highest ranking response to the quantitative survey question, "Why didn't you report all of your concussions?" was included along with the following criteria for participant selection:

1. Noted reported history of concussion.

2. Indicated lack of concussion reporting for concussions sustained.

3. Ranked "I was into the practice/game and didn't realize I had a concussion" as primary reason for not self-reporting concussion.

4. Indicated concussion education was received from an athletic trainer and/or coach.

5. Agreed to participate in a follow-up, in-person interview.

Criteria 1-4 were met by 18 participants, of which 9 agreed to participate in phase II of the study.

\section{Instrumentation}

Phase I participants completed an online survey which included four components: demographic information, exposure to concussion education, concussion history and the Rosenbaum Concussion Knowledge and Attitudes Survey (RoCKAS-ST), ${ }^{17}$ a measurement of concussion knowledge and attitudes. Psychometric evaluation of validity found the 55-item RoCKAS-ST to be a "useful tool in the evaluation of knowledge about etiology, course, and sequelae of concussion as well as the assessment of attitudes about concussion and reporting management" (ref. 17, p. 51). Higher scores on the knowledge index are associated with greater concussion knowledge, and higher scores on the attitude index are associated with safer attitudes about concussion.

Questions developed for the interview guide for phase II of the study were informed by phase I results. Interview questions addressed the following areas: concussion education received by participant, risks of concussion, participant concussion experiences, not recognising concussion despite having received concussion education, and teammate and coach attitudes about 
concussion. The guide was examined by three reviewers experienced with qualitative research and the topic of study, and piloted with three collegiate student-athletes who were not part of the study. The finalised interview guide contained 29 open questions and was administered by the PI at the participants' respective colleges.

\section{Data analysis}

Quantitative data were analysed using SPSS V.21. $\alpha$ level was set at $\leq 0.05$, with the exception of post hoc tests, where Bonferroni adjustment was made a priori with $\alpha$ set at 0.008. Non-parametric tests were conducted, as data were not normally distributed as verified by Kolmogorov-Smirnov test, which yielded statistical significance. Kruskal-Wallis test was performed to compare dependent variable medians. Post hoc tests were conducted using the Mann-Whitney $U$ test for performing pair wise comparisons. Regressions were performed to determine predictive value of independent variables upon dependent variables.

Audio recordings from interviews were recorded and transcribed. Qualitative data analysis included the "core tasks in the analytic cycle: description, comparison, categorization and theory development" (ref. 18, p. 234). Using interpretative thematic analysis approach, and two passes of the data, one reviewer placed data into chunks and coded, and two reviewers developed the thick descriptions and synthesised the data into themes. Links among data categories were identified in the process leading to conceptualisation of qualitative results. ${ }^{19}$ Trustworthiness of qualitative results was established through triangulation of quantitative and qualitative data, peer debriefing, inquiry audit and reflexive journaling. ${ }^{20}$

\section{RESULTS}

\section{Phase I}

\section{Concussion education}

Concussion education was received by $70 \%$ (692) of participants at least once in the past 5 years. Of the participants who received concussion education, $85 \%$ (578) were educated within the last year. Education was most frequently received through an athletic trainer (figure 1). The format in which education was disseminated included

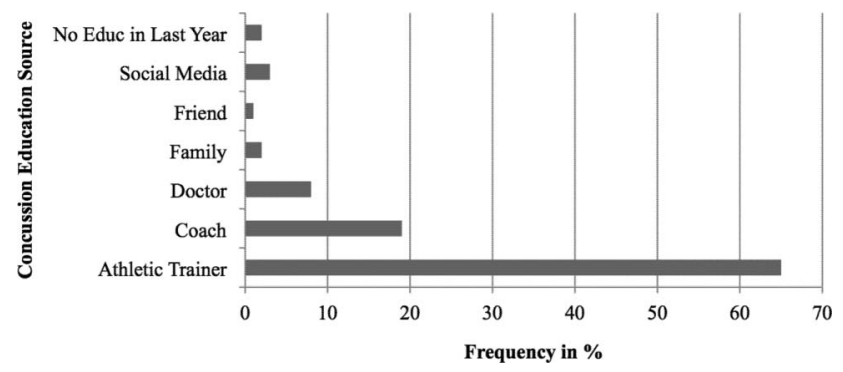

Figure 1 From whom have you received the most education on concussion in the past year? (Select one). in-person lecture/presentation $(66 \%, 452)$, hand-outs $(27 \%, 184), 1: 1$ conversation $(24 \%, 165)$ and online $(22 \%, 150)$. Kruskal-Wallis test showed that exposures to education between teams were significantly different (table 1). Post hoc comparisons using the Mann-Whitney $\mathrm{U}$ test indicated number of exposures to concussion education was significantly greater for participants who played football. Participants who played football received concussion education a significantly greater number of times than men's soccer $(\mathrm{N}=510, \mathrm{~m}=350, \mathrm{~N}=163, \mathrm{~m}=295$; $\mathrm{p}=0.00)$, men's water polo $(\mathrm{N}=510, \mathrm{~m}=304, \mathrm{~N}=58, \mathrm{~m}=184$; $\mathrm{p}=0.00)$, women's water polo $(\mathrm{N}=510, \mathrm{~m}=295, \mathrm{~N}=47$, $\mathrm{m}=188 ; \mathrm{p}=0.00)$ and volleyball $(\mathrm{N}=510, \mathrm{~m}=306, \mathrm{~N}=62$, $\mathrm{m}=191 ; \mathrm{p}=0.00$ ).

\section{Reporting of concussion history}

A history of concussion was reported by $38 \%$ of respondents. ('History of concussion' was defined in the survey as 'concussions that may or may or may not have been diagnosed by a physician'.) Kruskal-Wallis test revealed statistical difference in concussion history between teams (table 1). Mann-Whitney U post hoc test indicated that number of concussions reported by participants who played football was significantly higher than men's soccer $(\mathrm{N}=510, \mathrm{~m}=350, \mathrm{~N}=163, \mathrm{~m}=295 ; \mathrm{p}=0.00)$ and men's water polo $(\mathrm{N}=510, \quad \mathrm{~m}=290, \quad \mathrm{~N}=57, \quad \mathrm{~m}=227$; $\mathrm{p}=0.00)$.

Of those respondents who reported a history of concussion, 36\% did not report all of the concussions sustained. Binary logistic regression indicated that history of concussion was predictive of reporting behaviour. Controlling for sport affiliation and gender, for every concussion participants sustained, the likelihood that participants would report increased by $63 \%$. Sport affiliation and gender were not associated with reporting behaviours (table 2). When asked, "Why did you report your concussions?" 48\% (102) selected "I didn't feel well and needed to let someone know", and 15\% reported the injury as a result of education received. The highest ranked reason (at 33\%) for not reporting concussion was "I was into the practice/game and didn't realize I had a concussion at the time" (table 3 ).

\section{Concussion knowledge}

The mean Concussion Knowledge Index score was 33/ $43(77 \%)$. The mean Concussion Attitude Index score was $47 / 75$ (63\%). Knowledge did not correlate

Table 1 Group comparisons for exposure to concussion education and number of concussions

\begin{tabular}{|c|c|c|c|}
\hline Variable & $\chi^{2}$ & df & p Value \\
\hline Exposure to concussion education & 89.69 & 5 & 0.00 \\
\hline Number of concussions & 21.68 & 5 & 0.00 \\
\hline
\end{tabular}


Table 2 Summary of binary logistic regression for variables predicting concussion reporting

\begin{tabular}{lllllll}
\hline Predictor & B & SE & df & p Value & $\mathbf{e}^{\mathbf{B}}$ & $\mathbf{9 5}^{\text {9 }} \mathbf{C l}$ \\
\hline Concussion knowledge & 0.10 & 0.06 & 1 & 0.11 & 1.11 & 0.97 to 1.27 \\
Number of concussions & 0.49 & 0.11 & 1 & 0.00 & 1.63 & 1.31 to 2.0 \\
Sport played & -0.09 & 0.11 & 1 & 0.40 & 0.91 & 0.73 to 1.13 \\
Gender & 0.43 & 0.42 & 1 & 0.30 & 1.54 & 0.67 to 3.57 \\
\hline
\end{tabular}

Table 3 Ranked \#1 reasons for not reporting concussion

\begin{tabular}{lll}
\hline Response $(\mathbf{n}=\mathbf{1 2 0})$ & Frequency & Per cent \\
\hline I was into the practice/game and didn't realize I had a concussion at the time & 40 & 33.33 \\
I knew I would be held out if I reported it & 25 & 24 \\
It didn't seem like a big deal & 19 & 20.83 \\
I didn't know what a concussion was at the time & 3 & 20.00 \\
I thought it would hurt my chances of being picked up by a 4-year school & 2 & 15.93 \\
I felt pressure from my coach not to report & 1 & 1.67 \\
I felt pressure from my teammates not to report & 0.83 \\
\hline
\end{tabular}

Table 4 Summary of multiple regression for variables predicting concussion knowledge

\begin{tabular}{lllllll}
\hline Predictor & B & SE & $\boldsymbol{\beta}$ & $\mathbf{t}$ & $\mathbf{p}$ & $\mathbf{9 5 \%} \mathbf{C l}$ \\
\hline Number of concussions & 0.01 & 0.06 & 0.00 & 0.18 & 0.85 & -0.11 to 0.13 \\
Number of times exposed to concussion education & 0.07 & 0.02 & 0.08 & 2.64 & 0.00 & 0.01 to 0.12 \\
\hline
\end{tabular}

significantly with reporting behaviours $(\mathrm{r}=0.06, \mathrm{n}=322$, $\mathrm{p}>0.05)$. There was a weak but statistically significant correlation between number of times that education was received $(\mathrm{r}=0.08, \mathrm{n}=914, \mathrm{p}<0.01)$ and level of concussion knowledge. A multiple linear regression was conducted to predict participants' concussion knowledge based on exposures to concussion education and history of concussions (table 4). For each exposure to concussion education, participant's knowledge score increased by 0.07 . Only $1 \%$ of total variability in knowledge score was explained by concussion education $\left(\mathrm{R}^{2}=0.01\right)$. History of concussion was not predictive of concussion knowledge. Multiple linear regression performed to determine predictive value of years playing sport, gender and team affiliation was not predictive of number of concussions reported by participants $(\mathrm{p}>0.05)$.

\section{Phase II}

Table 5 provides a description of the nine interview participants reflecting respective sport, number of years playing sport, number of times concussion education was received and history of concussion as reported on quantitative survey. Most participants had experienced multiple concussions.

All participants in phase II reported having received concussion education, and eight of nine indicated on the survey that they 'agreed' or 'strongly agreed' that the education was adequate and one participant disagreed. During the interviews, all made reference to the risks or seriousness of concussion. Qualitative data analysis revealed two categories that addressed why participants did not realise a concussion might have been sustained despite having received concussion education: a perceived physiological response precluding the student-athlete's ability to identify possible concussion, and attitudes that mitigated acknowledgement and self-reporting of a possible concussion. These experiences were described by participants as occurring in practice and competition, but were much more common and intense in competition. Themes identified under the category of physiological response included 'adrenaline' and being 'in the zone'. Themes identified under attitudes included 'selfevaluation', 'sense of duty and commitment to team' and 'denial' (figure 2).

\section{Physiological response}

Adrenaline

The in vivo reference of 'epinephrine' was mentioned by participants in the context of describing competition and the experience of pain (or lack thereof), with a resultant inability to identify a potential concussion. Participants described sustaining a concussion and not experiencing symptoms until the competition was over:

I just kept going through and didn't realize until after the game. I think it was like the adrenaline pumping... I finished it out and after I just felt awful. I just couldn't focus, couldn't do anything. (Participant \#2)

\section{Being 'in the zone'}

All participants made reference to the impact of being 'in the zone' during competition, especially in regard to 
Table 5 Description of phase II participants

\begin{tabular}{lllll}
\hline Participant & Sport & $\begin{array}{l}\text { No. of years } \\
\text { playing sport }\end{array}$ & $\begin{array}{l}\text { No. of times concussion } \\
\text { education received }\end{array}$ & $\begin{array}{l}\text { No. of } \\
\text { concussions }\end{array}$ \\
\hline 1 & Football & 14 & 5 & 3 \\
2 & Women's volleyball & 5 & 2 & 2 \\
3 & Football & 11 & 4 & 3 \\
4 & Women's water polo & 1 & 5 & 2 \\
5 & Football & 5 & 2 & 1 \\
6 & Football & 4 & 5 & 6 \\
7 & Women's water polo & 8 & 1 & 1 \\
8 & Football & 5 & 5 & 2 \\
9
\end{tabular}

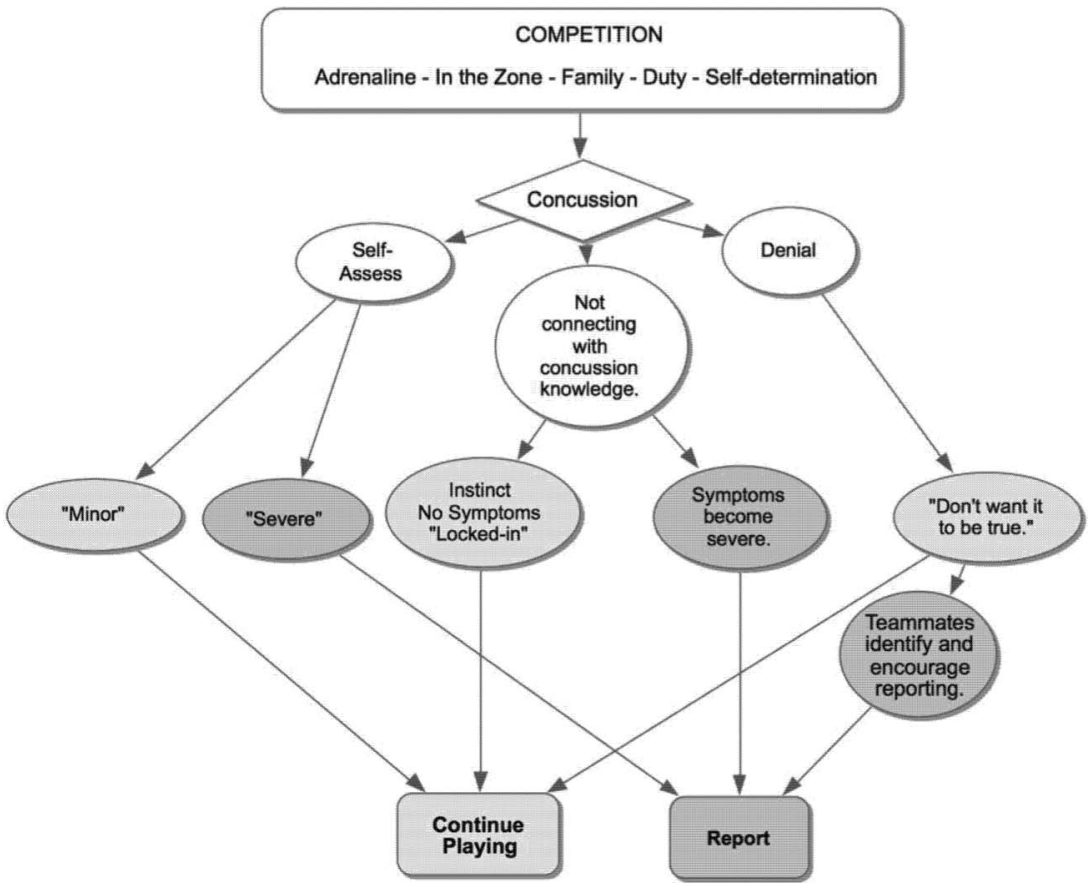

Figure 2 Understanding reporting behaviours of participants who were 'into the competition' and did not realise they had a concussion.

injuries, including concussion. A narrowed but more powerful focus, feeling physically and mentally stronger, and operating on 'instinct' were discussed as part of the 'in the zone' experience. Reliance upon intuitive physical responses, versus higher level cognitive skills, was mentioned by several participants. Participants explained how competition fully engaged their focus and that the concussion education they received did not seem accessible, or was overpowered by an inner drive: "It's almost like instinct... like something triggers it. Then... I'm not really thinking, just doing" (Participant \#7).

\section{Attitudes mitigating concussion reporting}

\section{Self-evaluation of symptoms}

Participants referenced a process of self-evaluation implemented if they suspected a concussion following a blow or hard hit. After testing themselves on a variety of cognitive and/or physical 'tests', they determined if the injury was 'minor' or 'severe'. 'Minor' concussions were not considered to be actual concussions worthy of reporting by the participants who self-assessed, resulting in continuing to play: "I felt it but, I'm still able to-I know it's Tuesday. I'm able to catch a pass. I'm able to play football. I know what my coach is saying. I know my name, like, I'll be fine" (Participant \#9).

\section{Sense of duty/commitment to team}

Participants who determined the injury to be 'minor' and therefore not a 'real' concussion also discussed the important role connection to the team or 'family' played in compelling them to continue to play without further attention to a suspected concussion. Paradoxically, participants also discussed being more likely to look out for the welfare of a teammate than for their own health: "You want to take care of your teammates because you do care about them and they are like your family. And, then when 
it [concussion] happens to you, you kind of shrug it off like it's no big deal" (Participant \#4).

\section{Denial}

Some participants indicated that they did not want to believe they had sustained a concussion, and so continued to play while denying a possible injury. "I didn't really acknowledge it. I just wasn't brave enough to say it because I didn't want it to be true" (Participant \#4).

\section{DISCUSSION}

\section{Summary of primary findings}

Almost three-fourths of participants reported receiving concussion education, and the primary mode for receiving this education was lecture. While number of exposures to concussion knowledge was positively correlated with concussion knowledge, greater concussion knowledge was not associated with increased reporting behaviours. The primary reason for not reporting concussion, despite having received education, was 'being into the practice/game'. Physiological and attitudinal influences were identified as barriers to reporting, including: 'adrenaline', being 'in the zone', 'self-evaluation', 'sense of duty to family team' and 'denial'.

\section{Transfer of concussion knowledge}

Results indicate that the ability to access concussion knowledge in a neurometabolic environment associated with competition-an environment altered by increased epinephrine and cortisol associated with competition ${ }^{21} 22$ and compromised by the sequelae of concussion-warrants examination. Participants indicated that while they were knowledgeable in concussion, during competition this knowledge was 'not relevant', a 'primal' inner drive that they associated with adrenaline 'took over', and they were 'not thinking, just doing'.

Kahneman's work describing 'fast and slow thinking' provides a context for understanding the experience of the student-athlete during competition. Kahneman divides cognitive processes into two systems. System 1, 'fast thinking', operates in an automatic, intuitive and involuntary manner, while system 2, responses to stimuli, is slow, deliberate and analytical..$^{23}$ Concussion knowledge is imparted (through lecture, hand-outs and online) with the expectation of a reasoned and deliberative response (slow thinking) by the student-athlete in the event of injury. This contrasts with the demands of competition which are fundamentally based on speed, in settings that are dynamic, with responses that are largely reactive. This has little resemblance to the measured and 'slow thinking' characteristics of the classroom environment in which concussion education often occurs. This brings into question the extent to which participating in competition affects the student-athlete's ability to transfer concussion knowledge, from the 'slow thinking' embodying concussion education to the intuitive and 'fast' nature of cognitive processing characteristic of competition.
Research on context-dependent memory addresses how information learnt in a different environment from where the information will be applied can diminish knowledge transfer. A seminal study by Godden and Baddeley, ${ }^{24}$ supported by more recent studies, ${ }^{25}{ }^{26}$ showed that 'recall is better if the environment of initial learning is reinstated'. These findings lead to the consideration that concussion knowledge might be better accessed when presented in the same venue in which recall is required (ie, the pool, the court and the pitch). However, context alone may not be enough to affect transfer of skills in a stressful situation such as competition. ${ }^{27} 28$

Most participants in this study received concussion education via lecture (declarative learning). In contrast, as participants described, their behaviours during competition were reliant upon the scores of practices based largely in procedural learning. Procedural learning, 'the capacity to acquire a skill through physical practice', is not dependent on the 'conscious recollection of facts' (ref. 29, p. 146), but rather is the result of learning kinaesthetic routines. Once learnt, these 'automatic' skills do not require the analytic properties of the frontal lobe to respond accordingly. Procedural learning is not reliant upon the higher cognitive processes often affected in brain injury, and it is a common learning approach used by clinicians in brain injury rehabilitation. ${ }^{29}$ In the field of nursing, such kinaesthetic simulations are considered to address the 'adrenaline gap' that occurs when nursing students 'underperform' in exercises where there is a lack of stress associated with the real event. ${ }^{30}$ The inclusion of procedural learning in concussion education in the actual setting of play warrants exploration to determine efficacy and viability. Such approaches would align with research supporting the effectiveness of a more interactive approach to concussion education. ${ }^{8}$

Procedural learning as part of concussion education can be implemented for each sport in the form of a non-contact drill. For example, for football, following dissemination of concussion education through lecture and/or video, drills take place on the football field according to position. The athletic training staff provides a signal indicating to a student-athlete that a concussion has occurred. The signalled student-athlete then provides the gesture for injury (eg, tapping top of helmet). The athlete progresses to the sideline reporting a previously agreed upon phrase, that is, "I think I need to be checked out." The drill is repeated several times, providing opportunity for experiential learning in the venue of play. The ability to involve coaches in such an activity addresses the cultural norm of acceptance and expectation of reporting behaviours.

\section{Importance of serial assessment}

Consistent with what has been described as the 'analgesia of competition' (ref. 31, p. 315), participants indicated that during games they did not experience pain 
and other symptoms that might be associated with a possible concussion. Those who did ultimately report their concussions did so: after competition when epinephrine had subsided, where symptoms had reached a point that they were intolerable, and with the urging of teammates. This finding supports recommendations in the literature that following suspected concussions, serial assessments of concussion should be conducted (including postgame when hormonal levels approach baseline), as symptoms may not be immediately present following injury. ${ }^{2}$

\section{'Minor' concussion and continued play}

Interviews revealed the process of self-assessment that participants underwent in determining that their concussion was 'minor', with resulting continued play. Knowledge was used to identify a potential concussive event, but instead of notifying the athletic trainers, participants were compelled, some by a sense of duty, to continue playing. This same sense of responsibility and connection to 'family' was associated with participants reporting a suspected concussion in a teammate. This behaviour is consistent with research on self-other risk-taking which demonstrated that individuals are less likely to make risk-taking decisions for others than themselves in scenarios involving physical safety. ${ }^{32}$ Furthermore, research on bystander intervention as it relates to concussion reporting has shown that the intention to report is greater when athletes believed that there was a significant negative impact on their teammate's health or performance. ${ }^{33}$ Finally, results indicate that some student-athletes may deny symptoms not only to medical staff but also to themselves. Consistent with the literature on psychology of injury, ${ }^{34}{ }^{35}$ some participants continued to compete because they were in denial and felt the possibility of concussion 'could not be true'.

\section{CONCLUSION}

Student-athletes may not be cognizant of a possible concussion particularly during the stress of competition. Epinephrine, being 'in the zone' and accommodation to pain may preclude athletes from identifying and reporting concussions. The ability for a student-athlete to break through the automaticity and emotionality of competition to indicate the need for concussion assessment is one of the barriers raised by participants in this study. The tendency for self-assessment, a behaviour that immediately followed participants' suspecting a concussion in this study, should be highlighted in educational programmes as a signal to report to a member of the sports medicine team for follow-up. Concussion education should also clarify the misconceptions of 'minor' concussion. Emphasis should be placed on the potential life-altering outcomes of 'playing through' symptoms that may initially be perceived by the student-athlete as mild or of little consequence.

Alternate methods of providing concussion education that can affect knowledge transfer should be explored and future research considered. Results of this study indicate that such approaches might include providing education in the settings in which student-athletes practice and compete, incorporating a kinaesthetic or procedural learning approach to concussion education, and addressing the social and attitudinal aspects of concussion reporting.

Contributors NRC was the primary investigator and involved in all aspects of the study, including methodology, data collection, analysis and interpretation, and was the primary author of the article. PP contributed to methodology, analysis and data interpretation, along with editing the manuscript for publication.

Funding This study was funded by the NASPA Channing Briggs Research Grant.

Competing interests None declared.

Ethics approval Sonoma State University Institutional Review Board.

Provenance and peer review Not commissioned; externally peer reviewed.

Open Access This is an Open Access article distributed in accordance with the Creative Commons Attribution Non Commercial (CC BY-NC 4.0) license, which permits others to distribute, remix, adapt, build upon this work noncommercially, and license their derivative works on different terms, provided the original work is properly cited and the use is non-commercial. See: http:// creativecommons.org/licenses/by-nc/4.0/

\section{REFERENCES}

1. Okonkwo DO, Tempel ZJ, Maroon J. Sideline assessment tools for the evaluation of concussion in athletes: a review. Neurosurgery 2014;75(Suppl 4):S82-95.

2. McCrory P, Meeuwisse WH, Aubry M, et al. Consensus statement on concussion in sport: the 4th International Conference on Concussion in Sport, Zurich, November 2012. J Athl Train 2013;48:554-75.

3. Legislatures NCoS. State laws on traumatic brain injuries: 2009-2014. Secondary State laws on traumatic brain injuries: 2009-2014, 2014. http://www.ncsl.org/research/health/traumatic-brain-injury-legislation. aspx

4. The National Collegiate Athletic Association. 2013-2014 NCAA Sports Medicine Handbook, 2013 (August):56-68. https://www.ncaa org/sites/default/files/2013-14\%20Sports\%20Medicine\% 20Handbook.pdf

5. California Community College Athletic Association. CCCAA Constitution and By-laws. By-law 9, Medical Policies, 2015:16. http://www.novatechsetproofs.com/epds/techsetepds/bmj/BMJSEM/ BMJSEM-2016-00011823082016191738419BMJ/bmjsem-2016000118.pdf

6. Tator $\mathrm{CH}$. Sport concussion education and prevention. J Clin Sport Psychol 2012;6:293-301.

7. Bramley H, Patrick K, Lehman E, et al. High school soccer players with concussion education are more likely to notify their coach of a suspected concussion. Clin Pediatr (Phila) 2012;51:332-6.

8. Caron JG, Bloom GA, Falcão WR, et al. An examination of concussion education programmes: a scoping review methodology. Inj Prev 2015;21:301-8.

9. Register-Mihalik JK, Linnan LA, Marshall SW, et al. Using theory to understand high school aged athletes' intentions to report sport-related concussion: implications for concussion education initiatives. Brain Inj 2013;27:878-86.

10. Torres DM, Galetta KM, Phillips HW, et al. Sports-related concussion: anonymous survey of a collegiate cohort. Neurol Clin Pract 2013;3:279-87.

11. Register-Mihalik JK, Guskiewicz KM, McLeod TC, et al. Knowledge, attitude, and concussion-reporting behaviors among high school athletes: a preliminary study. J Athl Train 2013;48:645-53.

12. Kroshus E, Baugh CM. Concussion education in U.S. Collegiate Sport: what is happening and what do athletes want? Health Educ Behav 2016;43:182-90.

13. Lawrence $\mathrm{HJ}$, Mullin CM, Horton D. Considerations for expanding, eliminating, and maintaining community college athletic teams and programs. New Dir Commun Coll 2009;147:39-51. http://dx.doi.org/ 10.1002/cc.376 
14. Bush VB, Castaneda C, Hardy DE, et al. What the numbers say about community colleges and athletics. New Dir Commun Coll 2009Fall:5-14.

15. Creswell J, Plano Clark VL. Designing and conducting mixed methods research. Thousand Oaks (CA): Sage Publications, 2007.

16. Merriam S. Qualitative research and case study applications. San Francisco (CA): Jossey-Bass, 1998.

17. Rosenbaum AM, Arnett PA. The development of a survey to examine knowledge about and attitudes toward concussion in high-school students. J Clin Exp Neuropsychol 2010;32:44-55.

18. Hennink M, Hutter I, Bailey A. Qualitative research methods. Thousand Oaks (CA): Sage Publications, 2011.

19. Carpenter C, Suto M. Qualitative research for occupational and physical therapists: a practical guide. Ames (IA): Blackwell Publishing, 2008.

20. Cope DG. Methods and meanings: credibility and trustworthiness of qualitative research. Oncol Nurs Forum 2014;41:89-91.

21. Aizawa K, Nakahori C, Akimoto T, et al. Changes of pituitary, adrenal and gonadal hormones during competition among female soccer players. J Sports Med Phys Fitness 2006;46:322-7.

22. Fernandez-Fernandez J, Boullosa DA, Sanz-Rivas D, et al. Psychophysiological stress responses during training and competition in young female competitive tennis players. Int $J$ Sports Med 2015;36:22-8.

23. Kahneman D. Thinking, fast and slow. New York (NY): Farrar, Strauss and Giroux, LLC, 2011.

24. Godden DR, Baddeley AD. Context-dependent memory in two natural environments: on land and underwater. Br J Psychol 1975;66:325-31.
25. Smith SM, Vela E. Environmental context-dependent memory: a review and meta-analysis. Psychon Bull Rev 2001;8:203-20.

26. Hockley WE, Bancroft TD, Bryant E. Associative and familiarity-based effects of environmental context on memory. Can J Exp Psychol 2012;66:81-9.

27. Schwabe L, Böhringer A, Wolf OT. Stress disrupts context-dependent memory. Learn Mem 2009:16:110-13.

28. Thompson LA, Williams KL, L'Esperance $\mathrm{P}$, et al. Context-dependent memory under stressful conditions: the case of skydiving. Hum Factors 2001;43:611-19.

29. Vidoni ED, Boyd LA. Achieving enlightenment: what do we know about the implicit learning system and its interaction with explicit knowledge? J Neurol Phys Ther 2007;31:145-54.

30. Maran NJ, Glavin RJ. Low- to high-fidelity simulation-a continuum of medical education? Med Educ 2003;37(Suppl 1):22-8.

31. Sternberg W. Pain, basic concepts. Psychological basis of sport injuries. Morgantown (WV): Fitness Information Technology, 2007:305-17.

32. Stone ER, Choi YS, Bruine de Bruin W, et al. I can take the risk, but you should be safe: self-other differences in situations involving physical safety. Judgm Decis Mak 2013;8:250-67.

33. Kroshus E, Garnett BR, Baugh CM, et al. Engaging teammates in the promotion of concussion help seeking. Health Educ Behav 2016:43:442-51.

34. Hanin Y. Emotions in sport. Champaign (IL): Human Kinetics, 2000.

35. Podlog L, Heil J, Schulte S. Psychosocial factors in sports injury rehabilitation and return to play. Phys Med Rehabil Clin N Am 2014;25:915-30. 